\title{
Comparison of strength values and laterality in various muscle contractions between competitive swimmers and untrained persons
}

\author{
Shinichi Demura ${ }^{1}$, Hiroki Aoki ${ }^{1}$, Yuta Yamamoto ${ }^{2}$, Shunsuke Yamaji ${ }^{3 *}$ \\ ${ }^{1}$ Kanazawa University, Graduate school of Natural Science \& Technology, Kanazawa, Japan; \\ ${ }^{2}$ Kanazawa Gakuin High School, Kanazawa, Japan; \\ ${ }^{3}$ University of Fukui, Faculty of Medical Sciences, Fukui, Japan; *Corresponding Author: yamaji@u-fukui.ac.jp.
}

Received 6 July 2010; revised 20 July 2010; accepted 2 August 2010.

\begin{abstract}
Competitive swimmers may gain a specific training effect as the result of long term exercise in the water. This study aimed to compare isometric, non-isokinetic and isokinetic muscle strengths in competitive swimmers and untrained persons. Twelve young male adults without exercise experience for over three years and twelve swimmers with over 10 years of competitive swimming experience performed various strength tests. Non-isokinetic tests were evaluated using one repetition of maximum half squat, vertical jump, and drop jump. Isometric and isokinetic (60 and $180 \mathrm{deg} / \mathrm{s}$ ) muscle strengths were measured by both legs in knee extension and flexion. There were no significant differences between nonisokinetic and isometric muscle strengths of both groups. On the other hand, all isokinetic parameters in both angular velocities were significantly larger in competitive swimmers. There was significant laterality of isokinetic strength in untrained persons, but not in competitive swimmers. In addition, right and left differences of isokinetic strength tended to be smaller in competitive swimmers. In conclusion, competitive swimmers tended to be superior only in isokinetic strength, which is a similar muscle contraction in the water, and have less right and left differences.
\end{abstract}

Keywords: Lsokinetic Strength; Lsometric Strength; Knee Extension and Flexion; Laterality

\section{INTRODUCTION}

The exercise training effect depends largely on the training method, i.e., training region, muscle contraction property, and work load as indicated by the principle of specificity of training [1]. Competitive swimmers gain a specific training effect which differs from other athletes as the water training environment requires nearly isokinetic muscle contraction $[2,3]$.

Muscle contraction on dry land is unlikely to be completely isotonic in all ranges of motion. In a narrow sense, the muscle tension in the latter output phase is allowed to be smaller based on the acceleration produced in the initial maximum output phase. However, in water, maximum muscle tension is also required in the latter output phase because the drag becomes loads in all ranges of motion [4]. That is, it is possible that competitive swimmers gain a training effect with superior muscle strength exertion during isokinetic contraction or in the latter range of motion as compared to other athletes on dry land or untrained persons. On the other hand, Taguchi [5] compared the eccentric and concentric muscle strengths of competitive swimmers and untrained persons and reported that the eccentric strength per body mass and eccentric/concentric strength ratio were inferior in swimmers. In addition, Tanaka and Swensen [6] pointed out that the incremental increases of muscle strength from traditional resistance training on dry land contributed little to the improvement of competitive swim performances and suggested that water training should be more swim-specific.

In short, previous studies [5-7] have examined eccentric and concentric muscle strengths of competitive swimmers and the influence of resistance training on dry land on swim performances. However they have not sufficiently studied the isokinetic muscle strength mainly used in water training.

Swimming is performed in either a supine or prone posture with a bilaterally-symmetric motion and is influenced by buoyancy. In other words, it is nearly unaffected by gravity and requires the same muscle exertion 
of both the right and left extremities [8]. On the other hand, most sports competitors on dry land in games involving balls mostly use the dominant extremities. In addition, behavior emphasizing the dominant extremity is performed frequently in daily living [9]. The laterality of muscle strength in competitive swimmers may be lower than that in other dry land athletes or untrained persons because they require the same muscle exertion in both the right and left extremities. However, this pro blem has not been thoroughly examined.

Some previous studies [5-7] hold a negative view of resistance training on dry land for swimmers because the muscle gains of swimmers differ from those of general competitors on dry land. If so, swimmer-specific resistance training protocols should be proposed. Moreover, most competitors using dominant extremities on dry land develop an imbalance of body alignment or injury [10]. If muscle output in swimmers' extremities remains balanced, swimming may play an important role in conditioning training to correct an alignment imbalance.

This study aimed to compare isometric, non-isokinetic and isokinetic muscle strengths of competitive swimmers and untrained persons.

\section{METHODS}

\subsection{Participants}

A group of 12 male competitive swimmers, experienced in competitive swimming 5 days a week for over a decade (mean $\pm \mathrm{SD}$, age: $20.0 \pm 1.4$ years, height: 172.8 $\pm 4.3 \mathrm{~cm}$, body mass: $67.7 \pm 6.6 \mathrm{~kg}$ ) and a group of 12 male individuals who had not exercised for the past three years (mean $\pm \mathrm{SD}$, age: $23.0 \pm 0.6$ years, height: $171.9 \pm$ $3.2 \mathrm{~cm}$, body mass: $64.6 \pm 6.4 \mathrm{~kg}$ ) participated in this study. There were no significant differences of age, height, and body mass between both groups. Participants received an explanation of the aims and methods of this study and signed an informed consent form. This study was approved by our University Committee on Human Research.

\subsection{Measurements Procedures of Muscle Strength Parameters}

Muscle strength was evaluated from non-isokinetic (one repetition of maximum half squat (1 RM half SQ), vertical jump, and drop jump), isometric and isokinetic knee extension and flexion muscle strength. Isometric and isokinetic muscle strength were measured in both the dominant and non-dominant legs. The dominant leg was defined as the leg used to kick a ball.

\subsection{Non-Isokinetic Muscle Strength}

1) One repetition of maximum half squat (1 RM half
SQ).

Regarding the non-isokinetic muscle strength, participants performed one repetition of maximum half squat (1 RM half SQ). A barbell was placed on a power rack at about $10 \mathrm{~cm}$ below the participants' shoulder height at the beginning of the test. The participants positioned themselves under the barbell, stood up, stepped a few steps back, squatted down (90 degree knee flexion) and stood up. Their feet position and grip width were self-selected. They placed the barbell on their upper trapezius muscle immediately below C7. They started the warm-up with sets of 1-5 repetitions with the bar only $(20 \mathrm{~kg})$. They then added weight of $20-40 \mathrm{~kg}$ in each set until the load became about $60 \%$ of the estimated $1 \mathrm{RM}$ and then added $5-10 \mathrm{~kg}$ until the load was $90 \%$ of the estimated $1 \mathrm{RM}$. After completing these sets, the weight was increased by 2.5 or $5 \mathrm{~kg}$ each set until their $1 \mathrm{RM}$ was determined. They were allowed to take as much rest as needed between sets to minimize the effects of fatigue.

\section{2) Vertical Jump}

The distal vertical jump meter (Jump distal MD, TAKEI, Japan) was used to measure the participant's vertical jump height. Participants performed two countermovement vertical jumps with arm-swing movements, and the higher value was used for statistical analysis.

3) Drop Jump

The distal vertical jump meter (Jump distal MD, TAKEI, Japan) was used to measure the participant's vertical jump height during the drop jump. Participants were asked to step off a $40 \mathrm{~cm}$ box and jump immediately after the landing, aiming to produce the maximum height while minimizing ground contact time. During this jump movement, their hands were kept on their hips. They performed the drop jump twice, and the higher value was used for statistical analysis.

\subsection{Lsometric Muscle Strength}

Isometric muscle maximum strength was measured at a knee angle of $1.309 \mathrm{rad}$ (75 degree) using an isokinetic dynamometer (Cybex-325, Lumex, USA) at $0 \mathrm{deg} \cdot \mathrm{s}^{-1}$. The participants performed this movement twice, and the larger value was used for statistical analysis.

\subsection{Lsokinetic Muscle Strength}

An isokinetic dynamometer (Cybex-325, Lumex, USA) was used to measure isokinetic maximum strength. Peak torque during knee extension and flexion at two angular velocities, $60 \mathrm{deg} \cdot \mathrm{s}^{-1}$ (five trials) and $180 \mathrm{deg} \cdot \mathrm{s}^{-1}$ (thirty trials) was measured as described previously [11]. The largest value was adopted as the peak torque for each angular velocity. In addition, the sum of total work in 30 trials was measured at $180 \mathrm{deg} \cdot \mathrm{s}^{-1}$. 


\subsection{Data Analysis}

The mean differences of non-isokinetic muscle strength parameters between the two groups were revealed with the student's t-test. Two-way repeated measures ANOVA (groups [swimmers and untrained persons] $\times$ measures [dominant and non dominant leg]) were used to compare mean differences of isometric and isokinetic muscle strength parameters. A Tukey HSD post-hoc test was used to localize differences. In addition, the mean difference of abmodality between both legs was examined with the student's t-test. In all statistical analyses, the 0.05 level of significance was adopted.

\section{RESULTS}

There were no significant differences between nonisokinetic muscle strengths for swimmers and untrained individuals (Table 1).

For isometric knee extension and flexion, there were no significant differences (Figure 1). On the other hand, for isokinetic knee extension peak torque, there were significant interactions in both angular velocities (60 deg $\cdot \mathrm{s}^{-1}: \mathrm{F}_{1,22}=9.45, \mathrm{P}=0.01,180 \mathrm{deg} \cdot \mathrm{s}^{-1}: \mathrm{F}_{1,22}=4.49, \mathrm{P}=$ 0.05 ) (Figure 2). In addition, there were significant group effects in both angular velocities for isokinetic knee flexion peak torque $\left(60 \mathrm{deg} \cdot \mathrm{s}^{-1}: \mathrm{F}_{1,22}=5.20, \mathrm{P}=\right.$ $\left.0.03,180 \mathrm{deg} \cdot \mathrm{s}^{-1}: \mathrm{F}_{1,22}=12.65, \mathrm{P}=0.00\right)$ and the sum of total work in both motions (Extension: $\mathrm{F}_{1,22}=7.98, \mathrm{P}=$ 0.01, Flexion: $\mathrm{F}_{1,22}=4.40, \mathrm{P}=0.05$ ) (Table 2). The post-hoc test revealed that all isokinetic parameters were significantly larger in the swimmer group and that peak torques by the dominant leg for extension (60 and 180 $\mathrm{deg} / \mathrm{s})$ and flexion $(60 \mathrm{deg} / \mathrm{s})$ were larger in the untrained persons group.

For abmodality between both legs in isometric parameters, there were no significant differences between both groups. However, for isokinetic parameters, there were significant differences between both groups in extension peak torque at both angular velocities and in flexion total work (Table 3).

\section{DISCUSSION}

Muscle cross-sectional area, neural adaptations, and the ratio of fast twitch fibers are the main determinants of maximum muscle strength and power [12]. Of them, the ratio of fast twitch fibers varies only slightly with acquired factors, such as training. Therefore, resistance training is conducted to improve other factors. Although the improvement of these physiological factors enhances strength performance, it is not always true that strength performance in all contraction types (isometric, isoki-

Table 1. Non-isokinetic strengths in untraiened persons and competitive swimmers.

\begin{tabular}{|c|c|c|c|c|c|c|c|}
\hline & \multicolumn{2}{|c|}{ Untrained persons $^{\mathrm{a}}$} & \multicolumn{2}{|c|}{ Swimmers $^{\mathrm{a}}$} & \multirow{2}{*}{$\mathrm{T}(22)$} & \multirow{2}{*}{$\mathrm{p}$} & \multirow{2}{*}{ ES } \\
\hline & $\mathrm{M}$ & SD & $\mathrm{M}$ & SD & & & \\
\hline 1RM half SQ (kg) & 107.5 & 21.6 & 97.9 & 19.9 & 1.130 & 0.271 & 0.46 \\
\hline Vertical jump $(\mathrm{cm})$ & 59.5 & 4.0 & 60.4 & 5.3 & 0.478 & 0.638 & 0.20 \\
\hline Drop jump (cm) & 55.6 & 5.2 & 56.2 & 3.5 & 0.320 & 0.752 & 0.13 \\
\hline
\end{tabular}

Note: $\mathrm{a}: \mathrm{n}=12$, M: mean, SD: Standard diviation, ES: Effect size

Table 2. Isometric and isokinetic strengths by dominant and non dominant legs in untrained persons and competitive swimmers.

\begin{tabular}{|c|c|c|c|c|c|c|c|c|}
\hline & \multicolumn{4}{|c|}{ Untrained persons $(\mathrm{n}=12)$} & \multicolumn{4}{|c|}{ Competitive swimmers $(\mathrm{n}=12)$} \\
\hline & \multicolumn{2}{|c|}{ Dominant } & \multicolumn{2}{|c|}{ Non dominant } & \multicolumn{2}{|c|}{ Dominant } & \multicolumn{2}{|c|}{ Non dominant } \\
\hline & M & SD & M & SD & M & $\mathrm{SD}$ & M & SD \\
\hline \multicolumn{9}{|l|}{ Isometric } \\
\hline Extension & 216.3 & 40.4 & 213.8 & 41.9 & 234.0 & 41.6 & 230.1 & 41.9 \\
\hline Flexion & 89.3 & 18.1 & 89.6 & 19.2 & 93.3 & 10.0 & 90.3 & 13.5 \\
\hline \multicolumn{9}{|l|}{ Isokinetic $60 \mathrm{deg} / \mathrm{s}$} \\
\hline Extension (peak torque) & 167.8 & 25.0 & 150.8 & 33.2 & 186.8 & 14.8 & 183.2 & 17.8 \\
\hline Flexion (peak torque) & 103.3 & 20.3 & 93.6 & 21.9 & 113.8 & 14.8 & 113.3 & 8.7 \\
\hline \multicolumn{9}{|l|}{ Isokinetic $180 \mathrm{deg} / \mathrm{s}$} \\
\hline Extension (peak torque) & 103.6 & 14.8 & 97.8 & 17.7 & 121.0 & 15.0 & 118.9 & 16.3 \\
\hline Flexion (peak torque) & 76.2 & 7.6 & 75.3 & 11.5 & 91.5 & 18.9 & 93.3 & 12.6 \\
\hline Extension (Sum of total work) & 2554.8 & 432.0 & 2489.3 & 395.9 & 2966.3 & 340.7 & 3013.2 & 486.6 \\
\hline Flexion (sum of total work) & 1925.1 & 325.7 & 1912.3 & 172.6 & 2148.3 & 457.4 & 2252.3 & 390.0 \\
\hline
\end{tabular}


Table 3. The abmodality between both legs about isometric and isokinetic parameters.

\begin{tabular}{|c|c|c|c|c|c|c|}
\hline & \multicolumn{2}{|c|}{ Untrained persons } & \multicolumn{2}{|c|}{ Competitive swimmers } & \multirow[b]{2}{*}{$\mathrm{t}$} & \multirow[b]{2}{*}{$\mathrm{p}$} \\
\hline & $\mathrm{M}$ & SD & $\mathrm{M}$ & SD & & \\
\hline \multicolumn{7}{|l|}{ Isometric } \\
\hline Extension & 14.9 & 12.6 & 17.3 & 15.3 & 0.41 & 0.687 \\
\hline Flexion & 7.3 & 6.9 & 6.6 & 5.2 & 0.30 & 0.767 \\
\hline \multicolumn{7}{|l|}{ Isokinetic $60 \mathrm{deg} / \mathrm{s}$} \\
\hline Extension (peak torque) & 16.9 & 13.1 & 6.8 & 4.3 & 2.55 & $0.018^{*}$ \\
\hline Flexion (peak torque) & 13.3 & 9.1 & 7.9 & 6.4 & 1.67 & 0.110 \\
\hline \multicolumn{7}{|l|}{ Isokinetic $180 \mathrm{deg} / \mathrm{s}$} \\
\hline Extension (peak torque) & 6.3 & 5.1 & 2.3 & 1.5 & 2.59 & $0.017 *$ \\
\hline Flexion (peak torque) & 9.9 & 7.8 & 11.1 & 7.6 & 0.37 & 0.714 \\
\hline Extension (Sum of total work) & 198.8 & 138.4 & 103.8 & 100.5 & 1.93 & 0.067 \\
\hline Flexion (sum of total work) & 265.2 & 172.2 & 118.3 & 143.3 & 2.27 & $0.033^{*}$ \\
\hline
\end{tabular}

*: $\mathrm{p}<0.05, \mathrm{M}$ : mean, SD: standard deviation.

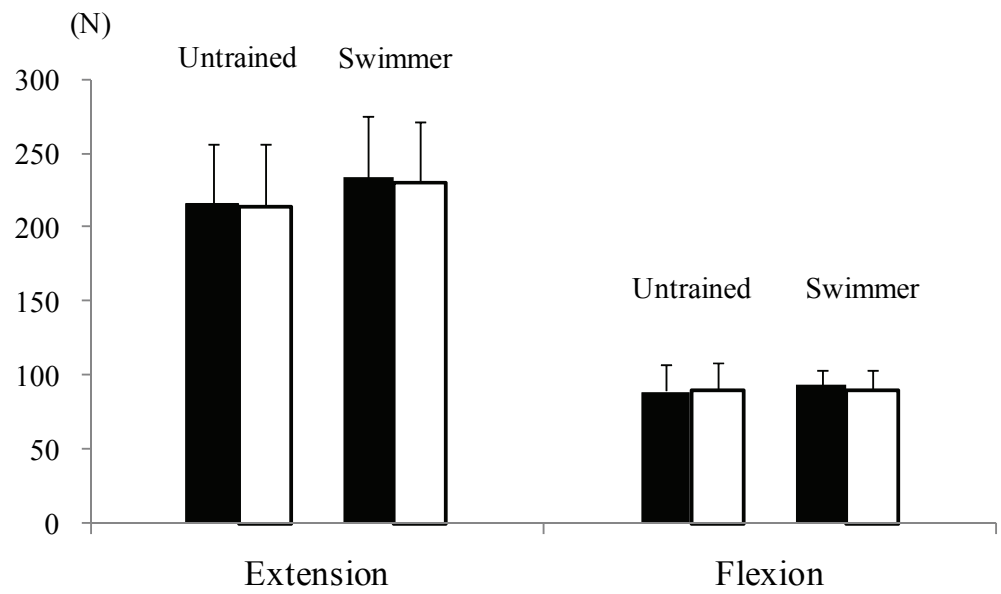

Figure 1. Isometric strengths by dominant ( $\square$ ) and non dominant ( $\square$ ) leg during knee extension and flexion in untrained persons and competitive swimmers.

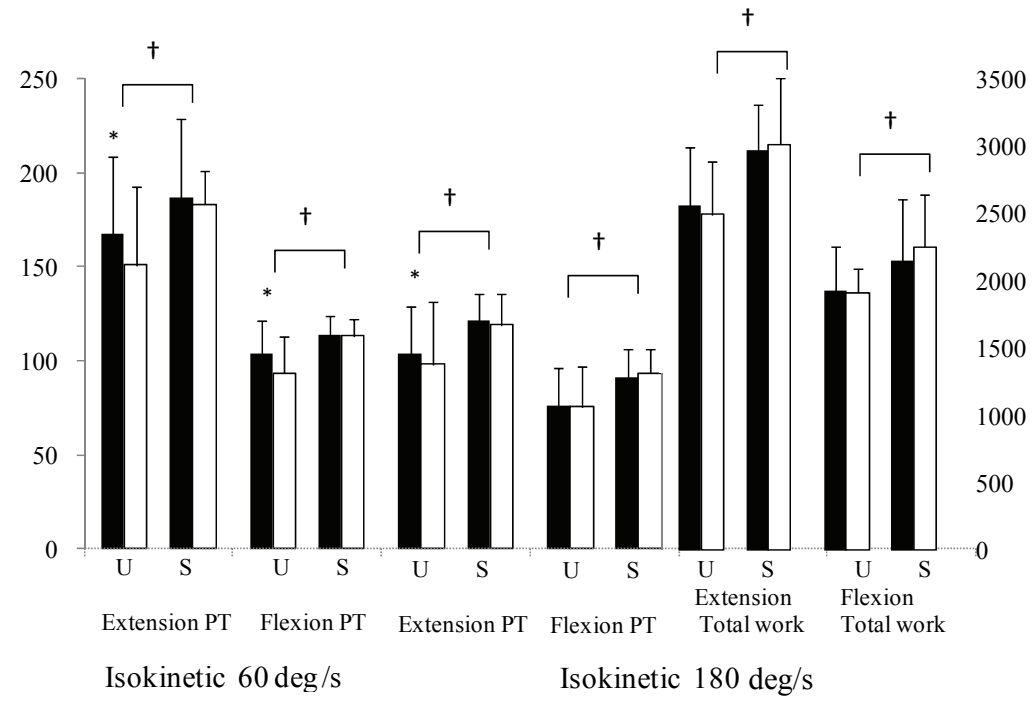

Figure 2. Isokinetic strengths by dominant (a) and non dominant ( $\square$ ) leg during knee extension and flexion in untrained persons and competitive swimmers. *: the peak torque was significantly larger in dominant leg. $\dagger$ : the torque was significantly larger in competitive swimmers. U: untrained persons, S: competitive. 
netic, isotonic, and eccentric contractions) are enhanced to the same degree [13]. In addition, the improvement ofstrength performance based on cross-sectional area may deteriorate swim performances because they are determined by the relationship between the propulsion produced by strength performance and passive drag [14]. It is recognized that the characteristic body shape of top competitive swimmers (slight build) is different than that of dry land athletes [15]. Therefore, competitive swimmers are a specific group that performs little resistance training on dry land and trains mainly in water using isokinetic contraction.

The improvement of strength performances depends strongly on muscle contraction type, intensity, and contraction velocity during training as indicated by the principle of specificity of training. Isokinetic contraction is required for maximum muscle exertion throughout the range of movement because the velocity of limb movement is constant, and the resistance is equal to the exerted muscle forces [16]. It was reported that isokinetic training improves the isokinetic output, such as the peak torque and the total work [17]. On the other hand, the relationship between isometric and isotonic strengths is very high, but these strengths are relatively low when compared to isokinetic strength [18]. Aagaard et al. [19] suggested that intraindividual differences of various muscle contraction types may be affected by training history or physical activity.

In this study, there were no significant differences of non-isokinetic (1 RM half SQ, vertical jump, and drop jump) and isometric knee extension and flexion strengths between both groups. Vertical jump and drop jump relate not only to lower limb strength and power, but also to the stretch-shortening cycle (SSC). Taguchi [5] reported that eccentric/concentric strength ratio was inferior in competitive swimmers than in untrained persons and suggested that competitive swimmers were inferior in muscle output using the SSC. Swimming, which is low intensity compared to muscle contraction and has few eccentric contraction phases, uses little muscle output during the SSC [5]. Therefore, competitive swimmers are not considered to gain a training effect on SSC output.

However, all isokinetic strength parameters in both angular velocities were superior in competitive swimmers. This suggests that maximum strength (peak torque) and muscle endurance (the sum of total work) in isokinetic contraction may be improved by swimming. It is unlikely that the difference of isokinetic strength in both groups was caused by organic differences of muscle (muscle fiber composition, cross-sectional area) because there was no significant difference in isometric strength. It may be the result of the lack of isokinetic contraction in the daily activities of untrained persons.

Kovaleski et al. [20] reported that isokinetic training enhanced the peak torque of isokinetic muscle output in low, moderate, and high angular velocities, but the improvement of isotonic strength was more suitable in isotonic training than in isokinetic training. This means that the training method to improve muscle performances depends largely on the aimed contraction type. Tanaka and Swensen's report [6] supported the above findings. They found that resistance training on dry land for competitive swimmers and untrained swimmers did not contribute to the improvement of swimming performances, despite substantially increasing upper body strength. In addition, they also reported that combined swim and swim-specific "in-water" resistance training programs improved the swimming velocity up to $200 \mathrm{~m}$ in competitive swimmers. Moreover, Neufer et al. [21] reported that muscle strength was maintained after reducing training volume or lack of training in competitive swimmers for 4 weeks, but the ability to generate power during swimming significantly decreased by $-13.6 \%$.

In short, competitive swimmers are considered to have improved isokinetic strength for swim performances rather than non-isokinetic and isometric strengths. However, from the present results, we can not infer that isokinetic strength training improves swimming performances. This issue should be examined in further studies.

We also compared the difference between dominant and non-dominant legs in isometric and isokinetic strengths. In untrained persons, isokinetic strength was significantly larger in the dominant leg than in the non-dominant leg. However, there was no significant difference in competitive swimmers. Previous studies $[22,23]$ reported that the laterality of leg strength was found not only in soccer players which use mostly the dominant leg but also in untrained persons. It should be noted that the laterality appeared only in isokinetic strength of untrained persons. Because they were not accustomed to isokinetic contraction, during which loads are imposed maximally in all ranges of motion, the difference of the operability of the dominant and nondominant legs may have appeared as a difference of force output.

Swimming performances do not place disproportionate emphasis on an extremity and require similar muscle exertion by both the right and left extremities. Therefore, there is no laterality of muscle strength. Rather, laterality of muscle strength may have a negative effect on swimming performances.

Also in the comparison of abmodality between right and left legs, competitive swimmers tended to decreased isokinetic muscle performances than untrained persons. 
Fine right and left balance of muscle strength is the result of swimming training.

In conclusion, competitive swimmers are superior to untrained persons in isokinetic strength at $60 \mathrm{deg} / \mathrm{s}$ and $180 \mathrm{deg} / \mathrm{s}$. There is a significant laterality of isokinetic strength in untrained persons but not in competitive swimmers. In addition, right and left differences of isokinetic strength tended to be smaller in competitive swimmers. These findings reflect the strength properties of competitive swimmers gained in training.

\section{REFERENCES}

[1] Morrissey, M.C., Harman, E.A. and Johnson, M.J. (1995) Resistance training modes: Specificity and effectiveness. Medicine and Science in Sports and Exercise, 27(5), 648660.

[2] Toussaint, H.M. and Hollander, A.P. (1994) Energetics of competitive swimming. Implications for training programmes. Sports Medicine, 18(6), 384-405.

[3] Pöyhönen, T., Keskinen, K.L., Kyröläinen, H., Hautala, A., Savolainen, J. and Mälkiä, E. (2001) Neuromuscular function during therapeutic knee exercise under water and on dry land. Archives of Physical Medicine and Rehabilitation, 82(10), 1446-1452.

[4] Pöyhönen, T., Kyröläinen, H., Keskinen, K.L., Hautala, A., Savolainen, J. and Mälkiä, E. (2001b) Electromyographic and kinematic analysis of therapeutic knee exercises under water. Clinical Biomechanics, 16(6), 496-504.

[5] Taguchi, M. (2002) Characteristic of eccentric and concentric muscular strength in knee extension-flexion on the competitive swimmers. Kyushu Yamaguchi Sports Medicine and Science, 14, 111-118.

[6] Tanaka, H. and Swensen, T. (1998) Impact of resistance training on endurance performance. A new form of crosstraining? Sports Medicine, 25(3), 191-200.

[7] Girold, S., Maurin, D., Dugué, B., Chatard, J.C. and Millet, G. (2007) Effects of dry-land vs. resisted- and assisted-sprint exercises on swimming sprint performances. Journal of Strength and Conditioning Research, 21(2), 599-605.

[8] Toussaint, H.M. and Beek, P.J. (1992) Biomechanics of competitive front crawl swimming. Sports Medicine, 13, 8-24.

[9] Demura, S., Yamaji, S., Goshi, F. and Nagasawa, Y. (2001) Lateral dominance of legs in maximal muscle power, muscular endurance, and grading ability. Perceptual and Motor Skills, 93(1), 11-23.
[10] Hogan, K.A. and Gross, R.H. (2003) Overuse injuries in pediatric athletes. The Orthopedic Clinics of North America, 34, 405-415.

[11] Kannus, P. (1994) Isokinetic evaluation of muscular performance: Implications for muscle testing and rehabilitation. International Journal of Sports Medicine, 15, 11-18.

[12] Hunter, G.R. (1987) Muscle physiology. In: Baechle, T.R. and Earle, R.W. Eds., Essentials of Strength Training and Conditioning, 2nd Edition, Human Kinetics, Champaign, 3-13.

[13] Knapik, J.J. and Ramos, M.U. (1980) Isokinetic and isometric torque relationships in the human body. Archives of Physical Medicine and Rehabilitation, 61, 64-67.

[14] Chatard, J.C., Bourgoin, B. and Lacour, J.R. (1990) Passive drag is still a good evaluator of swimming aptitude. European Journal of Applied Physiology and Occupational Physiology, 59, 399-404.

[15] Troup, J.P. (1999) The physiology and biomechanics of competitive swimming. Clinics Sports Medicine, 18(2), 267-285

[16] Baltzopoulos, V. and Brodie, D.A. (1989) Isokinetic dynamometry, applications and limitations. Sports Medicine, 8(2), 101-116.

[17] Lesmes, G.R., Costill, D.L., Coyle, E.F. and Fink, W.J. (1978) Muscle strength and power changes during maximal isokinetic training. Medicine and Science in Sports, 10(4), 266-269.

[18] Knapik, J.J., Wright, J.E., Mawdsley, R.H. and Braun, J.M. (1983) Isokinetic, isometric and isotonic strength relationships. Archives of Physical Medicine and Rehabilitation, 64, 77-80.

[19] Aagaard, P., Simonsen, E.B., Trolle, M., Bangsbo, J. and Klausen, K. (1996) Specificity of training velocity and training load on gains in isokinetic knee joint strength. Acta physiologica Scandinavica, 156(2), 123-129.

[20] Kovaleski, J.E., Heitman, R.H., Trundle, T.L. and Gilley, W.F. (1995) Isotonic preload versus isokinetic knee extension resistance training. Medicine and Science in Sports and Exercise, 27(6), 895-899.

[21] Neufer, P.D., Costill, D.L., Fielding, R.A., Flynn, M.G. and Kirwan, J.P. (1987) Effect of reduced training on muscular strength and endurance in competitive swimmers. Medicine and Science in Sports and Exercise, 19 (5), 486-490.

[22] Agre, J.C. and Baxter, T.L. (1987) Musculoskeletal profile of male collegiate soccer players. Archives of physical medicine and rehabilitation, 68, 147-150.

[23] Housh, D.J., Housh, T.J., Johnson, G.O. and Chu, W.K. (1992) Hypertrophic response to unilateral concentric isokinetic resistance training. Journal of Applied Physiology, 73, 65-70. 